INTERNATIONAL DESIGN CONFERENCE - DESIGN 2018

https://doi.org/10.21278/idc.2018.0388

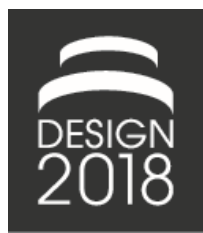

\title{
MAKING PARTNERSHIPS WORK: INTEGRATIVE OPEN SYSTEM DESIGN FOR A NEW GENERATION OF COMPLEX INFRASTRUCTURE SCHEMES
}

\author{
P. Witz and J. Oehmen
}

\begin{abstract}
With the financial crisis having casted doubt on many standard business models a search for adaptations began. Infrastructure investments around the world have produced rather mixed results. Previous research identified the main success/failure factors. At the same time, stakeholders' perception of risks has evolved having unforeseen implications. Our findings indicate that in order to bring risks under control and to secure a wider value creation, a new open system design needs to be applied in the process of planning, funding and managing complex transport infrastructure schemes.
\end{abstract}

Keywords: open system design, cost management, multi-/cross-/trans-disciplinary approaches, performance indicators, transport infrastructure

\section{Introduction}

The way we design our infrastructure should change. The stakes involved are high. Satisfying the growing needs for infrastructure development worldwide will require on average 6.3 trillion of investment every year between 2016 and 2030 (OECD, 2016). Transport infrastructure makes up almost half of that amount. Yet, there is a consensus the costs can be significantly lowered with improved management and engineering practices. For example, McKinsey \& Co. (2013) suggest there is a potential for savings equal to one third of current infrastructure expenses if appropriate measures are implemented. The improved performance, according to the study, stands and falls among other things on a profound change in design of infrastructure projects.

In fact, deficiencies in overall planning and design are likely to have contributed to numerous failures of large engineering projects all around Europe ranging from empty-shell nuclear power plants (Kolb, 2007) through underused railways (Carpintero and Petersen, 2014) and motorways (Acerete et al., 2009) to 'ghost' airports (Pisonero and Escolano, 2013). Most of these 'white elephant' projects ended up in failure due to poor system thinking and inexistent model for involving a wider spectre of stakeholders in decision-making, particularly during the early design phases of the project. At the same time, infrastructure projects of strategic importance suffer from poor performance and cost overruns due to among other things unnecessary social resistance (Scott, 2011) on the one hand or the lack of appropriate democratic oversight on the other.

This lack of exposure to the "outer world" of the project is likely to have played a role in causing major part of infrastructure projects to suffer from optimism bias (Flyvbjerg et al., 2005) or the fact that the best-case scenario is frequently considered the base-case one (Estache et al., 2008). Economic downturns, such as the most recent crisis have highlighted the short-comings of this approach expressed, principally, in risk adverse behaviour (Roumboutsos, 2013), unfavourable contract renegotiations 
(Guasch, 2003, 2004; Vassallo, 2006; Guasch et al., 2006, 2007), hold-up situations (Nikolaidis and Roumboutsos, 2013) and unavailability of finance at viable conditions.

This paper explores the potential of a new open system design approach as a solution to the main risks and failure factors associated with complex transport infrastructure schemes. It draws on previous research on infrastructure projects' failures and risk perception surveys with the experienced infrastructure professionals and experts. Based on a thorough analysis of the most pertaining failure factors and stakeholders' requirements in complex Public-Private Partnerships (PPPs), a new holistic approach to infrastructure is proposed that may provide "planning gains", demonstrate better value-formoney as well as reduce overall risk.

The following Section 2 explains the difference between the open and closed system thinking in infrastructure design. Section 3 goes on by illustrating the difference with the example of PPP schemes. Section 4 introduces methods used in this paper. Section 5 then presents findings concerning the main PPP risks and success/failure factors that are framed in Section 6 to create the new integrative open system design for infrastructure projects.

\section{Closed and open systems}

Traditionally, project management has viewed infrastructure projects as 'closed systems'. Yet, 'open system' design approaches have long been put forward as an alternative (see Katz and Kahn, 1978; Moore, 2002; Sussman et al., 2007). The idea was to improve the performance of a project and its more natural integration into the sociotechnical network by exposing it to the wider context of the system and its individual elements from its very inception, i.e. during the projects design phase. Apart from this basic characteristic, there has been a relative lack of detail as to what the open system design actually represents in terms of concrete measures affecting infrastructure-related processes.

For some, open system design is merely about enabling a wide spectre of stakeholders to have their say during the pre-/procurement phases of a project. For others, openness is a basic precondition for coordinated integration of all sociotechnical elements surrounding an individual project, or in fact a whole cluster of interrelated projects. Integration is a frequently advocated principle in transport policy as only through integration transport (and transport infrastructure) may deliver the anticipated benefits. Hull (2005) assessed the level of holistic integration by forming a "ladder of integration" with physical and operational integration of transport services as level (1) to integration of policies in all accompanied sectors as level (8).

Findings by Dimitriou et al. (2013) indicate the relation between Mega Transport Projects and broader spatial/sectoral design. The research confirmed that projects applying so called open perspective at the design stage are more likely to be successful than projects constantly treated as closed systems. It is because they enable 'a greater understanding of the actual and potential interactions of the project with its context, thereby allowing for unanticipated outcomes to be better discerned and accepted as part of an 'emergent order' (Dimitriou et al., 2013, p. 15). Overall success is defined with respect to economic, environmental, social and institutional sustainability.

Choosing the right approach is not easy : closed system projects (emphasis on the specific infrastructure without its sociotechnical context) are considered to provide greater "control" (Dimitriou et al., 2013), while in practice overall risk is decreased when considering wider systems, as a wider portfolio of options, i.e. solution space, is created during the design phase. This holds true in particular when stakeholder engagement comes into question.

\section{Public-Private Partnerships}

This paper uses transport infrastructure PPPs as the main unit of evaluation for their high aspirations and even bigger expectations placed upon their capacity for innovation and increasing efficiency of infrastructure procurement. Perhaps most importantly, the very label imply 'the public' has an important role to play in PPPs. But is that really the case?

In a way, PPP is the most complex and sophisticated method of procuring an infrastructure project. The term PPP in this context represents a "co-operation of some sort of durability between public and private actors in which they jointly develop products and services and share risks, cost and resources which are connected with these products" (Van Ham and Koppenjan, 2001, p. 598; see also Klijn and Teisman, 
2005). The "co-operation" is expected to produce value-added outcomes and efficiency gains. In addition, transport projects bear multiple impacts and are designed not only to address the principal issue of demand in transportation but also to weigh out, minimize or improve external present and future effects on time saving, air quality, noise, safety, energy consumption, economic growth, land use and real estate development. This wider "value" creation (in monetary and other terms) to society is usually not included in the PPP contract. Contrary to Weihe's (2008) interpretation, it does not confine itself to material and procedural public values, but includes all potential benefits to the society. These external benefits are not "planned for" in the design of a usual PPP project. They are left to market actors and society, in general, to "seize opportunities" and create the "anticipated" value. The problem is that with a closed system approach to PPPs the spillover effect may never materialize. Could that be that the closed system approach poses a harm to the overall PPP project success?

Analysing PPPs in urban regeneration, Boxmeer and Beckhoven (2005) distinguished between so-called 'strong partnerships' with a power-balanced situation where decision rights, costs and risks are shared among the individual stakeholders, and 'weak partnerships' where all the important competences are concentrated - very often in the hands of a single actor. Strong open partnerships tend to prevail in countries with a long tradition of consociational democracies and consensual decision making. On the other hand, weak (closed) partnerships are dominant in countries with more centralized or authoritarian models of government. To advance our thinking on benefits of either the open, or closed approach, it is therefore crucial to assess which of the two models has been more successful.

\section{Methods}

This paper merges the outcomes of an extensive comparative case study of PPP failure rates/factors and a unique risk perception survey among PPP professionals and uses them to construct the characteristics of a new open system design model. The initial and most important step in the analysis is to frame the problem in a way that allows us to use appropriate tools and most efficient methods for solving it. On the one hand, there is a set of real transport infrastructure projects in Europe procured as PPPs since the year 2000 that have been studied and classified over the period from 2012 to 2016 . We have got basic information about the entire population - which means we are able to say what proportion of them have been an outright failure and what percentage have been a relative success (meaning the projects were not cancelled, significantly modified at a late stage of implementation or bailed out by the government). There is also a sample of PPPs that have been analysed in some more detail bearing crucial pieces of information on factors that determine success/failure of a PPP project. At the same time, we can build on the outcomes of a survey among 22 transport PPP professionals from 13 countries on perception of risks associated with infrastructure PPPs and ideas how to mitigate them.

Data on cancelled projects are not systematically collected and published. For obvious reasons, representatives of the public administration in most countries prefer not to boast of projects that failed to meet the expectations. Thus to obtain the data, it was necessary to contact the responsible local organizations directly or through mediation of local collaborator in the form of a request under the freedom of information act of a given country. Parts of the puzzle had already been available from database collected within the COST Action 1001 or BENEFIT project in which case it was sufficient to confirm or update the figures. All responsible organizations without exception were asked the same question - i.e. what is the status of transport PPP projects launched and how many of these were cancelled between 2000 and 2016 in the given jurisdiction, what kind of projects were these and what were the circumstances of the demise of the PPP. Respondents were encouraged to distinguish between one immediate/primary cause of failure and if relevant also secondary factors that also played their part in project's demise (these could be several). All 17 authorities provided their responses. In most cases some follow-up questions were send out for harmonization and specification purposes. In the end, a relatively comprehensive overview of PPP failures across most European countries was achieved.

In the following step, the main sources of implementation deficit are identified and discussed. The overview from the previous phase indicates which countries experienced most problems implementing PPPs. The next part is focused on bringing the implementation deficit in the context of institutional framework of a given country with respect to the political system and governance regime in general. This section discusses the effects of the political system of the country, level of managerial capacities 
and in-house competencies to monitor implementation of PPPs as well as related legislative and procedural requirements in a given jurisdiction. The aim is to find a relationship between high number of PPP failures and relatively weaker institutional framework and, at the same time, to reveal factors, which in turn lead to relatively smooth and successful implementation of PPPs.

The present analysis of findings is based on a series of structured interviews. Their scope was to register stakeholders' (experts') shifts in the assessment of the risks involved in transport PPPs. Therefore, interviewees were selected to have significant experience prior to $2007 / 8$ and continue to be active in the sector. As risks are contextually assessed, interviewees were asked to focus on a specific project and country and assess risks for this project today, as well as register what the respective assessment was (or would have been) prior to the crisis. This quota significantly limited the number of potential interviewees as very few people in the public sector could comply with the pre-requisites, due to position - rotation in the public sector. In the private sector, while less difficult, there were restrictions due to the downturn in the international market.

Regardless, the 22 interviewees reflect 254 years of cumulative experience in PPPs and 362 years, respectively, in the transport sector or the average interviewee had 11.5 years of experience in PPPs and 16.5 years of experience in the transport sector. In addition, geographical variety of the sample (13 countries in total) allowed for an initial segmentation in Sovereign debt crisis countries (SDCC) and not (non-SDCC). When it comes to respondents' current affiliation and background, the sample is evenly split between the public and private sector. One needs to understand though that fluctuation between the two sectors occurs on regular basis. The exact composition of the sample is shown in the Table 1.

Table 1. Geographical and sectoral composition of the sample (Source: Witz and Roumboutsos, 2016)

\begin{tabular}{|l|l|l|l|}
\hline Country & No of respondents & Affiliation & No of respondents \\
\hline Greece (SDCC) & 4 & State & 11 \\
\hline Albania (non-SDCC) & 3 & SPV & 1 \\
\hline Spain (SDCC) & 3 & Lender & 1 \\
\hline Portugal (SDCC) & 2 & Sponsor & 3 \\
\hline UK (non-SDCC) & 2 & Advisor/consultant & 4 \\
\hline Czech R. (non-SDCC) & 2 & Other & 3 \\
\hline Belgium (non-SDCC) & 2 & & \\
\hline France (non-SDCC) & 1 & & \\
\hline Brazil (non-SDCC) & 1 & & \\
\hline Africa (non-SDCC) & 1 & & \\
\hline Sweden (non-SDCC) & 1 & & 22 \\
\hline Total & 22 & Total & \\
\hline
\end{tabular}

The ultimate objective was to identify shifts in stakeholders' assessment of risk probability and impact. These shifts either reflect changes to be anticipated in the financial/contractual PPP structure; problems encountered in the participants' experience in PPP's or an evolution in risk perception based on acquired experience and increased level of trust/ maturity of the PPP model (or the opposite). This defines risk perceptions, expressed as assessments of probability of occurrence and level of impact (severity) as latent variables dependent on personal overall experience and background as well as the transport sector and the political and macroeconomic conditions of the country/region wherein the project is implemented.

Interviewees were presented with a risk register. For all risks listed, they were asked to assess the probability of occurrence on a qualitative five (5)-point scale and, then, the potential impact of realized risks on a similar qualitative scale.

The idea of this study is to combine the empirical knowledge on success/ failure factors in PPPs with the findings about risk perception to provide an ideal infrastructure project design that could then be used in all sorts of circumstances. 


\section{PPP risk \& success/failure factors}

The results of the comparative analysis reviewing PPP failure rates across 17 European nations are summarized in the Figure 1. First obvious conclusion is that transition countries from in particular Central and Eastern Europe region feature the highest PPP failure rates while having implemented low numbers of projects in contrast to countries from the North of Europe that, while having similarly low PPP activity, have so far managed to set most, if not all their PPPs on a steady course to success. From countries that practice PPP in transport more extensively, it is mainly the Mediterranean countries that saw the largest proportion of unsuccessful PPPs. From more mature PPP markets, the Netherlands excels with a high number of transport PPPs commenced and no major failure so far. Nevertheless, it is the focus on quality, rather than on quantity that keeps the failure rate close or equal to zero.

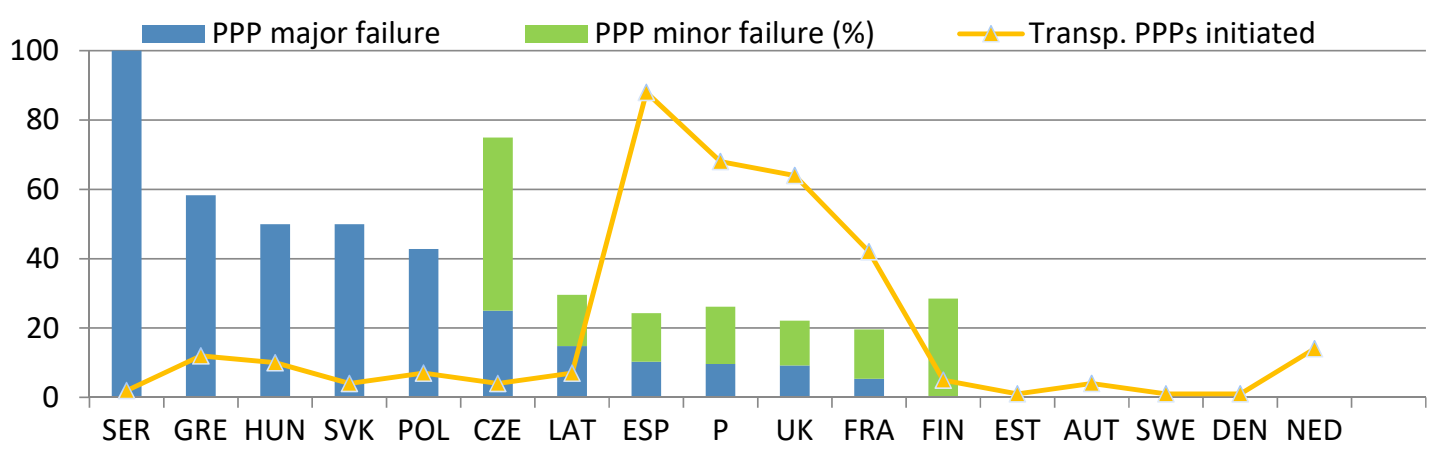

Figure 1. PPP failure rate/PPP initiated (Source: Witzova and Witz, 2017)

The main failure factors, i.e. the immediate/primary and contributory/secondary causes of PPP failure as identified by Witzova and Witz (2017) can be divided into five categories that are listed in Table 2. Interestingly, the prevalent failure factors overlap quite nicely with the results of PPP risk perception survey for the most significant risks. The scores for each of the risks associated with the given failure factor are also included in Table 2.

It was anticipated that financial and financing-related risks would appear high on the list of the most serious risks. Similarly, all types of demand related risk are also perceived as both particularly likely and potentially damaging for PPPs in SDCCs with general economic background, which involves traffic growth risk linked to macroeconomic factors causing more fear than any other category of risks. This is not surprising, given the fact that most tolled and other non-availability based PPP contracts, in particular in south Europe, underwent re-negotiation or were struggling due to the impact of the economic downturn on traffic volumes and cash flows.

It is in a sharp contrast with the perception of experts interviewed in non-SDCCs. Their concerns lay mainly in the sphere of politics - government stability and the willingness to honour/manage contracts. Probability of this kind of risk in non-SDCCs has surged during the crisis while its impact remained fairly serious with no major increase. When the PPP experience of CEE and some south European countries gets compared with that of countries with the lowest failure scores it becomes evident that what distinguishes the two is not the existence of specific PPP-dedicated organizations or laws but rather the stability and predictability of stakeholders' behaviour and actions ensured by established standards, mechanisms, procedures and a functional system of infrastructure procurement that is completely independent from political turbulences and based on professional and uniform process of project planning, assessment and multilateral dialogue. The system depends on qualified staff and advanced tools for communication with stakeholders and data management that together facilitate continuous advances and improvements to institutional memory and mutual trust among partners.

To some the high score for perception of social risk - both in probability and impact - in SDCCs may come as a surprise, but after the manifestation of popular initiatives such as No vull pagar in Catalonia or similar activities in Greece and the general increase in number of people refusing (or even not being able) to pay tolls at the toll collection points in the debt-struck countries, the risk of a rise of social movements boycotting the mechanisms of PPP projects on a large scale cannot be underestimated, let alone ruled out. Quite understandably, the social risk is not considered such an issue in non-SDCCs. 
Nevertheless, the awareness of potential public resentment has led several governments to delay or abandon any plans for introduction of tolls on highways. In the Czech Republic, for example, the availability payment mechanism is seen as the only politically acceptable solution when PPP is considered as an option for transport infrastructure projects (Witz, 2013).

Despite non-negligible amount of failure, there are several positive examples of PPP setup that can become components of the new open and holistic infrastructure project design. These success factors are listed in the Table 3. Furthermore, apart from the existing arrangements we also summarized suggestions put forward by the participants of risk perception survey (see Table 4). Together, the existing best practice and new proposed measures represent antidotes to above mentioned failure factors.

Table 2. Main PPP failure factors and risks (Source: Authors basing on Witzova and Witz, 2017)

\begin{tabular}{|c|c|c|c|c|c|}
\hline Failure factor/Risk & Description & $\begin{array}{l}\text { Primary } \\
\text { factor }\end{array}$ & $\begin{array}{l}\text { Secondary } \\
\text { factor }\end{array}$ & $\begin{array}{l}\text { Countries } \\
\text { most } \\
\text { affected }\end{array}$ & $\begin{array}{l}\text { Risk prob/impact } \\
\text { (1 least sign-5 } \\
\text { most sign.) }\end{array}$ \\
\hline $\begin{array}{l}\text { Failed demand } \\
\text { projections (traffic } \\
\text { volumes) }\end{array}$ & $\begin{array}{l}\text { optimism bias and flawed risk } \\
\text { projections - best case scenario }\end{array}$ & $35,3 \%$ & $7,5 \%$ & $\begin{array}{l}\text { ESP, GRE, } \\
\mathrm{P}\end{array}$ & $3,53 / 3,8$ \\
\hline $\begin{array}{l}\text { Funding and } \\
\text { financing related } \\
\text { problems }\end{array}$ & $\begin{array}{l}\text { inability to form successful } \\
\text { lender syndication, interest rate } \\
\text { volatility, market event or } \\
\text { funding shortage risks }\end{array}$ & $21,2 \%$ & $36,1 \%$ & $\begin{array}{l}\text { GRE, P, } \\
\text { ESP, HUN }\end{array}$ & $3,51 / 3,73$ \\
\hline $\begin{array}{l}\text { Inappropriate } \\
\text { political } \\
\text { interference }\end{array}$ & $\begin{array}{l}\text { Project cancellation or costly late } \\
\text { change as a result of political } \\
\text { instability }\end{array}$ & $24,6 \%$ & $16 \%$ & $\begin{array}{l}\text { CZE, HUN, } \\
\text { SVK, POL }\end{array}$ & $3,13 / 3,23$ \\
\hline $\begin{array}{l}\text { Inadequate } \\
\text { governance }\end{array}$ & $\begin{array}{l}\text { insufficient managerial } \\
\text { capabilities }\end{array}$ & $10,7 \%$ & $28,6 \%$ & $\begin{array}{l}\text { CZE, HUN, } \\
\text { SVK, }\end{array}$ & $3,52 / 3,2$ \\
\hline Social resistance & $\begin{array}{l}\text { From passive opposition } \\
\text { (boycotting the project) to active } \\
\text { (e.g. refusal to pay tolls during } \\
\text { operation, demonstrations } \\
\text { preventing construction, claims } \\
\text { in court against project et.al.) }\end{array}$ & $2,9 \%$ & $28 \%$ & $\begin{array}{l}\text { GRE, ESP, } \\
\text { HUN }\end{array}$ & $3,12 / 3,1$ \\
\hline
\end{tabular}

Table 3. Success factors

\begin{tabular}{|l|l|l|}
\hline Success factor & Description & Countries implemented \\
\hline $\begin{array}{l}\text { Depoliticization and } \\
\text { objectivization }\end{array}$ & $\begin{array}{l}\text { Consensual decision making on PPPs with an adequate } \\
\text { process of stakeholders consultations } \\
\text { Decisions on PPPs taken after reaching a consensus } \\
\text { among stakeholders - protection from later unwelcomed } \\
\text { interferences }\end{array}$ & NED, UK, FRA \\
\hline $\begin{array}{l}\text { High quality, empowered, } \\
\text { optimal-sized and well- } \\
\text { positioned infrastructure } \\
\text { procurement (PPP) units }\end{array}$ & $\begin{array}{l}\text { Capabilities to make better decisions based on thorough } \\
\text { evaluation of facts and more precise projections }\end{array}$ & NED, B, F, ESP \\
\hline $\begin{array}{l}\text { Standardization, } \\
\text { integration and clustering }\end{array}$ & $\begin{array}{l}\text { Replication of successful models, clustering and } \\
\text { integration of similar or related activities }\end{array}$ & NED, B, UK \\
\hline $\begin{array}{l}\text { Democratization, } \\
\text { transparency and } \\
\text { participation }\end{array}$ & $\begin{array}{l}\text { Openness to all relevant stakeholders, project } \\
\text { documentation in public domain, stakeholder } \\
\text { engagement activities }\end{array}$ & NED, UK \\
\hline $\begin{array}{l}\text { Shift from real toll to } \\
\text { availability-based models }\end{array}$ & Eliminate the risk of overoptimistic traffic projections & Several \\
\hline
\end{tabular}


Table 4. Proposals by PPP professionals (Source: Authors basing on Witz and

Roumboutsos, 2016)

\begin{tabular}{|l|l|}
\hline 1 & Cluster interconnected, similar and otherwise related projects! \\
\hline 2 & $\begin{array}{l}\text { New model of infrastructure financing involving new types of investors and shareholders like pension } \\
\text { funds, governments or users + greater direct financial responsibility for contractors and banks }\end{array}$ \\
\hline 3 & Long term plan for government investments and political consensus \\
\hline 4 & Better specification, planning and evaluations by the government \\
\hline 5 & Simplification and stabilization of legal framework for infrastructure projects \\
\hline 6 & Greater transparency \\
\hline
\end{tabular}

Knowing the nature of the main risks and having the overview of best practice countermeasures - both already applied or newly proposed by experts - we need to create a frame in which all these elements are combined in a meaningful way. We need a design that would enable us to see both the risks and opportunities for their mitigation in the context and to set up processes in the new system preventing the risks causing another major failure of an infrastructure project.

\section{Integrative open system design for infrastructure}

To effectively mitigate the design-phase risks discussed above, this paper explores the application of Open System Design to PPP infrastructure projects. As such, it combines the main strengths of existing institutional settings with recommendations by PPP professionals for additional improvements. The proposed model illustrated in Figure 2 resembles a magnetic field around a bar magnet. While south pole of the magnet represents open approach during design phase of an infrastructure project - basically an integration and engagement propeller - attracting and integrating various opportunities for increased social value, the north pole works effectively to repel various risks facing the project during its life cycle.

The proposed model views the development of infrastructure as an "organisation" able to create and deliver value aiming at addressing all potential uncertainties by taking into account and actively accumulating and assessing all relevant opportunities, More specifically, a common approach to reducing risk is to create a respective portfolio of activities that have a different source of risk and/or that may address the vulnerabilities of the project in the portfolio. In the case of infrastructure, delivery may be reflected in putting forward a combination of projects or in other words an integrated transport project.

It is clear that any new design for taking decisions on infrastructure investments should in the first place strive to review and innovate the financing mechanism as it lies at the very heart of the institutional settings. Traditional PPP funding structure got severely criticized for its fragility and overreliance on a closed ring of project creditors and investors whose risk exposure and interest in a PPP success is limited.

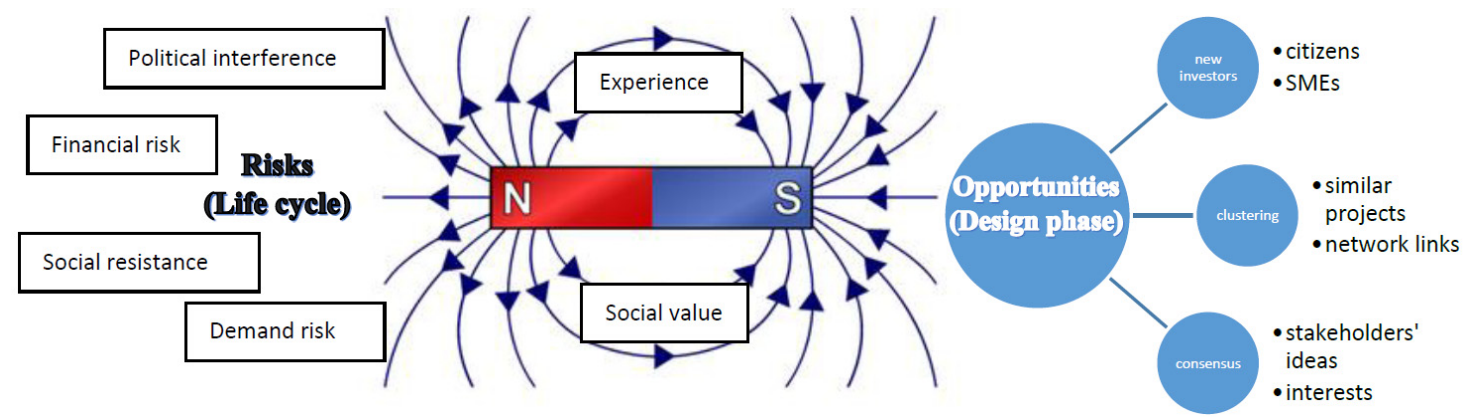

Figure 2. Open system design for infrastructure projects (Source: Authors)

Thus, in recent times, we have seen attempts to widen and transform the spectre of PPP shareholders to open up the system to as many sources of funding as possible thus breaking the impression of an exclusive club created around traditional actors in a PPP arena. The trend is illustrated in Figure 4. The 
UK's PF2 was one of the pioneering models in this respect although the initiative perhaps did not go as far as it could. With this process also comes a realization that the old model of transferring responsibility and risks from both government and contractors to a half-empty shell called Special Purpose Vehicle (SPV) should perhaps be replaced by a more proactive role of all parties concerned expressed by increased equity stakes of both government and contractors and proper representation of both public and private bodies in the project steering board.

At the same time, apart from attracting pension funds and other institutional investors the same effort should be invested in reaching out to non-institutional investors - ordinary citizens, SMEs who until now could not think of taking part in an investment syndicate like this. These people may live or operate in the area of a future construction site and may very well oppose the project as it is proposed right now. What would happen to their resentment once they got a unique opportunity to personally earn from the project's success?

\section{PPP integrated financial mechanism}

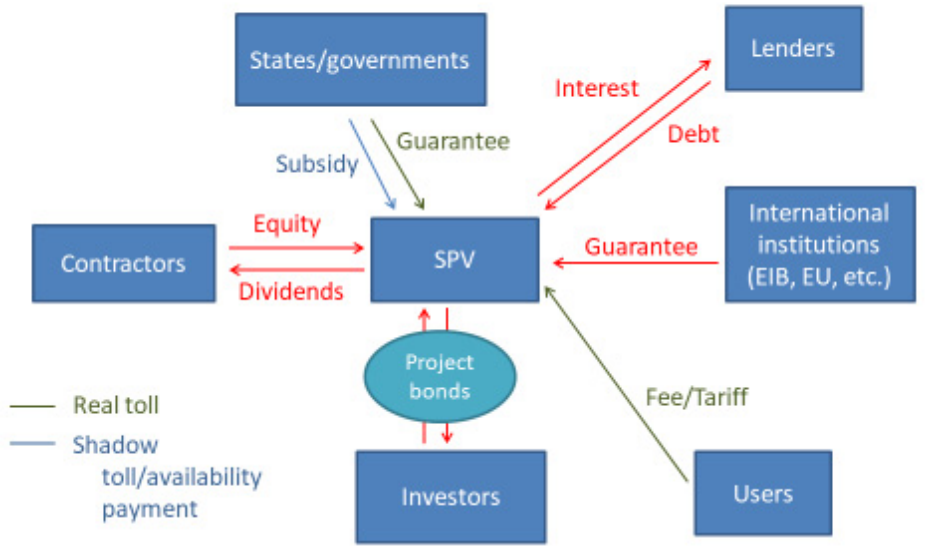

Figure 3. PPP integrated financial mechanism (Source: Authors)

There are numerous examples of various types of integration from the real world of transport infrastructure projects. An interesting account of innovative funding mechanisms which used in the state of Virginia in the USA was given by Ohlms (2013). In the absence of sufficient support for the development of local road networks from the state level, the local authorities were forced to come up with their own solutions and combinations to allow for the construction of key infrastructure. Several projects in Virginia made use of a balanced combination of instruments involving motivated contributors including developers, revenue sharing funds and to a certain extent also users and the direct project beneficiaries in the area. In most cases described by Ohlms, the local authorities were able to capture future revenue growth for their projects either through application of service districts, tax increment financing or more rarely impact fees. Use of proffers in certain parts of Virginia even helped the growth to mitigate its impact by making the developers consider the wider consequences of their projects. The success of these initiatives was contingent upon forward looking planning and negotiation during the land development process and an intensive vertical and horizontal communication and collaboration among experienced and capable partners on the state and local levels. Integration and careful planning taking into account maximum of possible consequences and externalities thus helped to reduce multiple risks usually involved in infrastructure projects and win the public approval.

In Europe, operational integration is common especially among urban public transport projects, terminals and to some extent also ports and airports (see for example Roumboutsos et al., 2013).

Quite understandably, in case of large urban projects with a high number of stakeholders and affected entities, it may be difficult to reach an agreement on sharing authority, risks and responsibilities. For example, it took a lot of effort and several delays before the balance acceptable to all parties was struck in the project of major redevelopment of Utrecht railway station and the surrounding area as the negotiations included 4 public and at least 8 private actors (Buijze, 2013). The resulting contract left no one in a dominant position, but made everyone contribute in a way to the project completion. 
Open system design thus requires willingness on the project coordinators' side to share their exclusivity and power in exchange for identification of unforeseen opportunities, additional resources and in most cases also significant risk mitigation. Relinquishing domination may not be an easy step for someone who is used to be in command and absolute control of things. Those project managers who are smart enough however recognize the value of tapping into a larger pool of ideas and expanding the sphere of their influence. It often takes no more than a simple change of attitude.

\section{Discussion and conclusion}

The potential of an integrative open system design for reducing social acceptance risk is enormous. Many examples from the real world show how much it depends on the attitude project advocates choose in relation to other stakeholders and general public in particular. As Dorst (2015) observes, a badly run problem-solving process in infrastructure projects "not only unnecessarily antagonizes people but, by putting them on the defensive, forces them into a very narrow behaviour pattern". The open design approach changes the focus from the infrastructure itself towards how it affects people's well-being and the ways it can benefit but also harm a wider sociotechnical network context. Being empathic about people's concerns and needs not only changes the tone and character of negotiations with stakeholders, but also opens new opportunities and thus unlocks value hidden in unrealized initiatives of once external actors. Tapping into the life of local communities, businesses and individuals also enables long-term planning by mapping and better understanding of social trends. Expert projections of future developments exposed to a broader audience of stakeholders have a much higher chance of being precise. While open system design not necessarily further increases the already high requirements on the range and quality of managerial capabilities both on public and private sector side, the ability to make all other risks more easily manageable is worth it.

The outcomes of our research show that ignorance of PPPs' wider context - both in terms of infrastructure and social interconnections often increases the already high probability and impact of associated risks beyond acceptable levels. Treating a PPP as an isolated island may bring about its eventual failure or deter potential stakeholders from engaging in PPPs at all.

Both the interviews with PPP professionals and cases discussed in this paper seem to hint that the future of major infrastructure projects lies in an integrative open approach that from the very beginning takes into account a wide context of related issues and partners from private and civic sectors. Closed systems and weak/uneven partnerships would need to be replaced by networks of motivated actors sharing both authority and responsibility for the project outcomes.

Further research should be launched into administrative and other costs comparisons between the two competing designs, but initial findings indicate that when it comes to the overall PPP success open system edges to victory.

\section{References}

Boxmeer, van B. and Beckhoven, van E. (2005), "Public-Private Partnership in Urban Regeneration: A Comparison of Dutch and Spanish PPPs", European Journal of Housing Policy, Vol. 5 No. 1, pp. 1-16.

Buijze, A. (2013), Case Study Utrecht Station Area, the Netherlands: How PPPs Restructured a Station, a Shopping Mall and the Law, CONTEXT Report 4, AISSR programme group Urban Planning, Amsterdam.

Carpintero, S. and Petersen, O.H. (2014), "PPP projects in Spain: evidence from light railway projects in Spain”, Public Money and Management, Vol. 34 No. 1, pp. 43-50.

Dimitriou, H.T., Ward, E.J. and Wright, P.G. (2013), "Mega Transport Projects - Beyond the 'iron triangle': Findings from the OMEGA research programme", Progress in Planning, Vol. 86, pp. 1-43.

Dorst, C.H. (2015), Frame innovation: create new thinking by design, MIT Press, London.

EPEC (2014), Market Update: Review of the European PPP Market in 2013, European PPP Expertise Centre, Luxembourg.

Estache, A., Guasch, J.L., Iimi, A. and Trujillo, L. (2008), Multidimensionality and Renegotiation: Evidence from Transport-Sector Public-Private- Partnership Transactions in Latin America, WB, Policy Research Working Paper 4665.

Flyvbjerg, B., Skamris Holm, M. and Buhl, S.L. (2005), "How (in)accurate are demand forecasts in public works projects? The case of transportation", Journal of the American Planning Association, Vol. 71 No. 2, pp. 131146. 
Guasch, J.L. (2003), "Infrastructure Concessions in Latin America and the Caribbean: The Renegotiation Issue and Its Determinants", Infrastructure and Financial Markets Review, Vol. 9 No. 2, pp. 1-6.

Guasch, J.L. (2004), Granting and Renegotiating Infrastructure Concessions: Doing it right, The World Bank, Washington, DC.

Guasch, J.-L., Laffont, J.-J. and Straub, S. (2006), "Renegotiation of concession contracts: A theoretical approach", Review of Industrial Organization, Vol. 1 No. 29, pp. 55-73.

Guasch, J.-L., Laffont, J.-J. and Straub, S. (2007), "Concessions of infrastructures in Latin America: Governmentled renegotiation”, Journal of Applied Econometrics, Vol. 22 No. 7, pp. 421-442.

Hull, A. (2005), "Integrated Transport Planning in the UK: From concept to reality", Journal of Transport Geography, Vol. 13 No. 4, pp. 318-328. https://doi.org/10.1016/j.jtrangeo.2004.12.002

Katz, D. and Kahn, R.L. (1978), The social psychology of organizations, John Wiley, New York.

Klijn, E.H. and Teisman, G.R. (2005), "Public private partnerships as the management of co-production: strategic and institutional obstacles in a difficult marriage", In: Hodge, G. and Greve, C. (Eds.), The Challenge of Public Private Partnerships: Learning from International Experience, Edward Elgar, Cheltenham.

McKinsey \& Co. (2013), Infrastructure productivity: How to save \$1 trillion a year. [online] McKinsey Global Institute. Available at: https:/www.mckinsey.com/industries/capital-projects-and-infrastructure/ourinsights/infrastructure-productivity (accessed 31.05.2017).

Moore, D.R. (2002), Project management: Designing effective organizational structures in construction, Oxford: Blackwell Sciencet Ltd.

Nikolaidis, N. and Roumboutsos, A. (2013), “A PPP renegotiation framework: a road concession in Greece”, Built Environment Project and Asset Management Journal, Vol. 3 No. 2, pp. 164-278.

OECD (2016), Technical note on estimates of infrastructure investment needs. [online] Available at: https://www.oecd.org/env/cc/g20-climate/Technical-note-estimates-of-infrastructure-investment-needs.pdf (accessed 03.11.2017).

Ohlms, P.B. (2013), "Local Government Funding and Financing of Roads in Virginia", International conference Global challenges in PPP: cross-sectoral and cross-disciplinary solutions?, Antwerp, Belgium, November 6-7, 2013.

Roumboutsos, A. (2013), "Private Finance of Transport Infrastructure: Shifts in Risk Perceptions; Initial Evidence", TRB 92nd Annual Meeting, Washington, DC, January 13-17, 2013.

Roumboutsos, A., Pellegrino, R., Vanelslander, T. and Macario, R. (2012), "Risks and Risk Allocation in Transport PPP projects: a literature review", In: Roumboutsos, A. and Carbonara, N., COST Action TU1001, Public Private Partnerships: Trends \& Theory, discussion papers.

Sussman, J., Dodder, R., McConnel, J., Mostashari, A. and Sgouridis, S. (2007), The CLIOS process: A user's guide, Massachusetts Institute of Technology, Cambridge, MA.

Van Ham, H. and Koppenjan, J. (2001), "Building Public Private Partnerships: Assessing and Managing Risks in Port Development”, Public Management Review, Vol. 3 No. 4, pp. 593-616.

Vassallo, J.M. (2006), “Traffic Risk Mitigation in Highway Concession Projects: The Experience of Chile”, Journal of Transport Economics and Policy, Vol. 40 No. 3, pp. 359-381.

Weihe, G. (2008), "Public-Private Partnerships and Public-Private Value Trade-Offs", Public Money and Management, Vol. 28 No. 3, pp. 153-158.

Witz, P. (2013), "PPP in the Czech Republic", In: Verhoest, K. et al. (Eds.), Public-Private Partnerships in transport: trends \& theory - country profiles, COST, Brussels.

Witz, P. and Roumboutsos, A. (2016), "Public Private Partnership Business Models for Transport Infrastructure", TRB conference, Washingtonu, DC, January 8th, 2016.

Witzova, P. and Witz, P. (2017), "Public Private Partnerships' failure rate in Europe compared: extent of transport PPPs' failure and its institutional determinants", Proceedings of the 12th International Scientific Conference Public Economics and Administration 2017, Technical University of Ostrava, Ostrava, Czech Republic, September 12-13, 2017.

Dr. Petr Witz, Postdoc

Technical University of Denmark, Management Engineering

Akademivej 385A, 2800 Kongens Lyngby, Denmark

Email: pwitz@dtu.dk 